\title{
Identification and analysis of Single Nucleotide Polymorphisms (SNPs) in the mosquito Anopheles funestus, malaria vector Charles S Wondji*, Janet Hemingway and Hilary Ranson
}

Address: Liverpool School of Tropical Medicine, Pembroke Place, Liverpool, L3 5QA, UK

Email: Charles S Wondji* - c.s.wondji@liverpool.ac.uk; Janet Hemingway - hemingway@liverpool.ac.uk;

Hilary Ranson - hranson@liverpool.ac.uk

* Corresponding author

Published: 04 January 2007

BMC Genomics 2007, 8:5 doi:10.1 |86/|47|-2/64-8-5

This article is available from: http://www.biomedcentral.com/I47/-2164/8/5

(c) 2007 Wondji et al; licensee BioMed Central Ltd.

This is an Open Access article distributed under the terms of the Creative Commons Attribution License (http://creativecommons.org/licenses/by/2.0), which permits unrestricted use, distribution, and reproduction in any medium, provided the original work is properly cited.
Received: 24 August 2006

Accepted: 04 January 2007

\begin{abstract}
Background: Single nucleotide polymorphisms (SNPs) are the most common source of genetic variation in eukaryotic species and have become an important marker for genetic studies. The mosquito Anopheles funestus is one of the major malaria vectors in Africa and yet, prior to this study, no SNPs have been described for this species. Here we report a genome-wide set of SNP markers for use in genetic studies on this important human disease vector.

Results: DNA fragments from 50 genes were amplified and sequenced from 21 specimens of $A n$. funestus. A third of specimens were field collected in Malawi, a third from a colony of Mozambican origin and a third form a colony of Angolan origin. A total of 494 SNPs including 303 within the coding regions of genes and 5 indels were identified. The physical positions of these SNPs in the genome are known. There were on average 7 SNPs per kilobase similar to that observed in An. gambiae and Drosophila melanogaster. Transitions outnumbered transversions, at a ratio of 2:I. The increased frequency of transition substitutions in coding regions is likely due to the structure of the genetic code and selective constraints. Synonymous sites within coding regions showed a higher polymorphism rate than non-coding introns or $3^{\prime}$ and 5 'flanking DNA with most of the substitutions in coding regions being observed at the $3^{\text {rd }}$ codon position. A positive correlation in the level of polymorphism was observed between coding and non-coding regions within a gene. By genotyping a subset of 30 SNPs, we confirmed the validity of the SNPs identified during this study.
\end{abstract}

Conclusion: This set of SNP markers represents a useful tool for genetic studies in An. funestus, and will be useful in identifying candidate genes that affect diverse ranges of phenotypes that impact on vector control, such as resistance insecticide, mosquito behavior and vector competence.

\section{Background}

Anopheles funestus and Anopheles gambiae are the major malaria vectors in Africa. Due to the difficulty of laboratory colonization, An. funestus has not received the same attention as An. gambiae and as a consequence there are few molecular markers for this species. However, the recent successful colonization of two strains of An. funes- tus [1] and the identification of a number of microsatellite markers [2,3] have facilitated more detailed studies of this species. Microsatellite markers particularly have been used to study population structure and gene flow between An. funestus populations [4-6] and a subset of these microsatellite markers were used to build the first linkage map of this species [7]. However, microsatellite markers 
are not evenly distributed across the genome, and their low number so far is an obstacle to the development of high resolution linkage maps needed for QTL mapping or association studies in An. funestus. Therefore, this study was initiated to increase the availability of characterized and mapped markers for An. funestus. Physically mapped ESTs were used to identify SNPs. Such ESTs have been used to study the genetic variability in a number of species such as Aedes aegypti, Drosophila melanogaster or Homo sapiens [8-10] and should be a source of DNA polymorphisms for An. funestus as well.

Single nucleotide polymorphisms (SNPs) are by far the most common type of molecular variation in all organisms. They are extremely abundant with an occurrence of about one SNP per kb in human [11] and about one SNP every 125 bp in An. gambiae [10]. Significant progress has been made in the development of tools for detection and genotyping of SNPs and they are now becoming the markers of choice for association studies, high-resolution linkage mapping and population genomics studies [12]. SNPs located in non-coding regions of the genome and synonymous SNPs (sSNPs) in coding regions, which have no impact on the phenotype, may provide useful markers for population genetics studies. Non-synonymous SNPs (nsSNPs) which alter the structure (change of amino acid sequence) and potentially the function of encoded proteins are useful markers for association studies to detect genetic variations linked with phenotypic traits.

Patterns of genetic diversity in An. funestus have not been studied to the same extent as in An. gambiae or Drosophila species. Nucleotide diversity in these species has been used to compare patterns of nucleotide variation, such as the relative occurrence of transitions/tranversions in different regions of the genome $[8,13]$. These surveys have established codon usage and usage bias patterns in many species, with bias hypothesized to occur as a result of selection for efficient translation $[14,15]$.

The sequencing of the 278 million base pairs (Mbp) constituting the An. gambiae genome has revealed more than 400,000 SNPs indicating a high level of polymorphism in mosquito species [16]. We hypothesize that by sequencing DNA fragments of different genes of An. funestus, a similar level of polymorphism should be encountered and will allow the identification of a significant set of SNPs.

Here, we describe the detection and characterization of a set of genome-wide SNP markers from 50 nuclear genes using two laboratory strains and field samples of $A n$. funestus. We also examined patterns of polymorphism and nucleotide diversity in coding and non-coding regions of the genome and define the pattern of codon usage in An. funestus. The utility of the SNPs was assessed by genotyping a subset of these SNPs during a linkage mapping study.

\section{Results and discussion Gene amplification}

In total, 70 primer pairs were tested by PCR, 55 of which gave reliable amplification with PCR products ranging from 194 to $1342 \mathrm{bp}$. Sequence data from a total of 21 specimens of An. funestus was obtained for 50 of these genes (see Table 1) from laboratory and field samples. Overall, we sequenced a total of 20,547 bp consisting of 14,671 bp of coding region and 5,876 bp of non-coding region. We identified 494 SNPs consisting of 303 coding SNPs (cSNPs) and 191 non-coding SNPs. Each gene contained at least one polymorphism with $B U 73$ having one and BU88 having 29. The distribution of SNPs among the 50 genes is presented in Table 1. All information concerning the location and the nature of each individual SNP have been submitted to dbSNP, the SNP database of GenBank. These SNPs with their respective reference SNP number (rs) are publicly available in dbSNP Build $\mathrm{N}^{\circ} 127$. The NCBI ss (submitted SNP) numbers of these SNPs are ss65917063 to ss65917416.

\section{Type of polymorphism}

For all sequenced DNA fragments, transition substitutions were more predominant than transversions (62\% vs $38 \%$ ). Transitions $\mathrm{C} \leftrightarrow \mathrm{T}$ and $\mathrm{A} \leftrightarrow \mathrm{G}$ are over-represented with 35.4 and $27.2 \%$ of the total substitutions respectively while the four transversion classes occurred at similar levels (Figure 1). The higher frequency of $\mathrm{C} \leftrightarrow \mathrm{T}$ and $\mathrm{A} \leftrightarrow \mathrm{G}$ SNPs is probably partly related to 5-methylcytosine deamination reactions that occur frequently, particularly at $\mathrm{CpG}$ dinucleotides [17]. The preponderance of transitions is more obvious for coding regions where out of the 303 SNPs identified, 201 were transitions $(66.3 \%)$ and 102 were transversions (33.7\%). The ratio of transitions/ transversions observed here is close to the $2: 1$ ratio observed for Drosophila and humans $[13,18]$. For polymorphism in non-coding regions, transitions accounted for 55\% (106) and transversion for 45\% (86). The frequency of transitions between coding and non-coding regions were significantly different ( $66.3 \%$ vs $55 \%$ respectively; $\left.\chi^{2}=5.86, P<0.01\right)$. This confirms that SNPs occur more frequently as transitions in coding regions than in non-coding regions. There is also a higher frequency of SNPs occurring at the third codon position $(63.7 \%)$ than at the $1^{\text {st }}$ or $2^{\text {nd }}$ position (Table 1 ). Similar results have been observed for Aedes aegypti [10] and in three species of Drosophila [13]. The degeneracy of the genetic code and the selective pressure for gene conservation have been suggested as the main reasons for the preponderance of transitions over transversions [13]. Synonymous or silent substitutions are more often transitions than transver- 
Table I: Nucleotide polymorphism in An. funestus genes

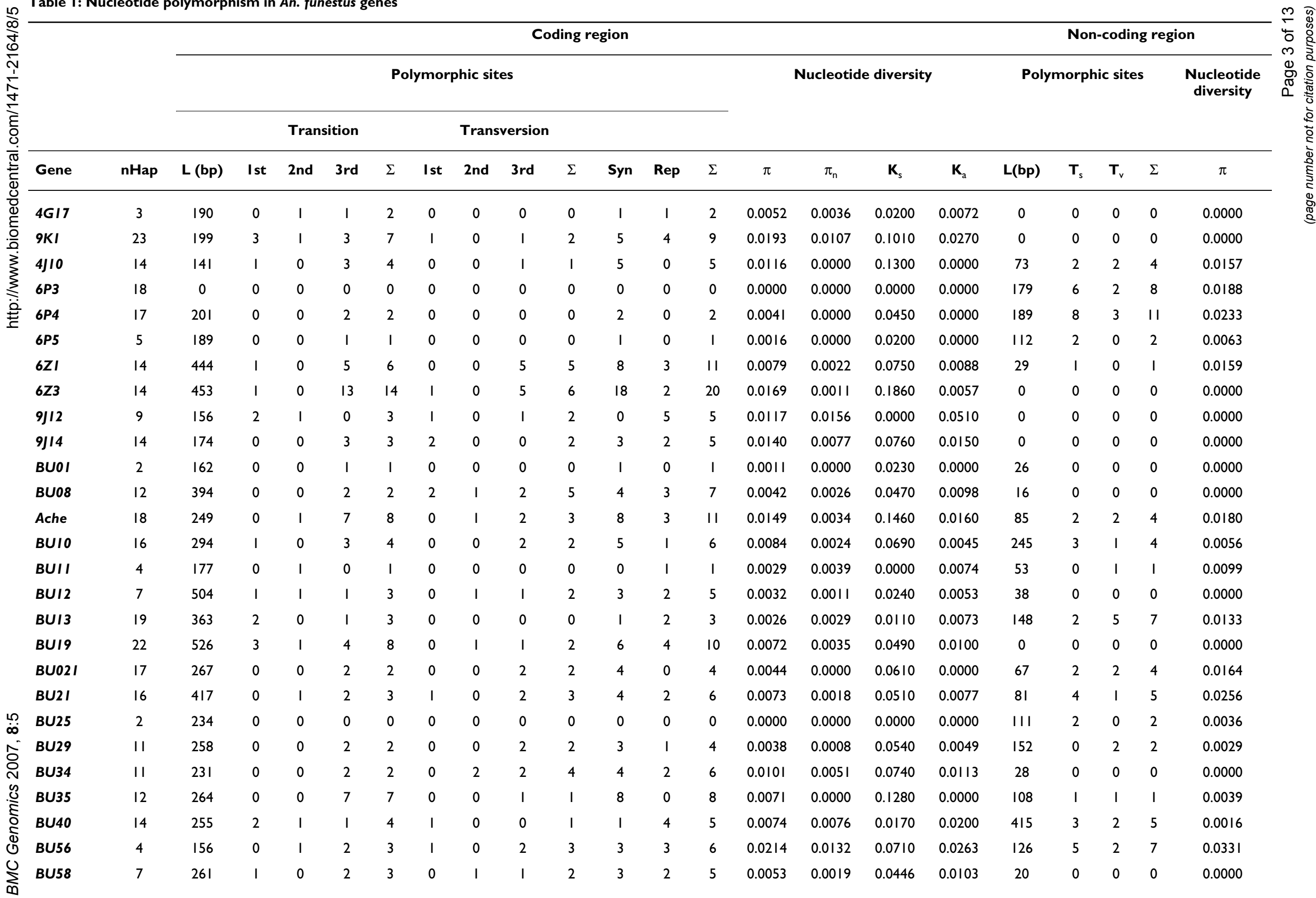


๒ Table I: Nucleotide polymorphism in An. funestus genes (Continued)

\begin{tabular}{|c|c|c|c|c|c|c|c|c|c|c|c|c|c|c|c|c|c|c|c|c|c|c|}
\hline BU62 & 22 & 213 & 0 & 0 & I & I & 0 & 0 & 0 & 0 & I & 0 & I & 0.0013 & 0.0000 & 0.0207 & 0.0000 & 260 & 7 & 5 & 12 & 0.0143 \\
\hline BU66 & 25 & 282 & 9 & 2 & 0 & 11 & 1 & 2 & 0 & 3 & 3 & 11 & 14 & 0.0174 & 0.0194 & 0.0503 & 0.0494 & 179 & 4 & 4 & 8 & 0.0099 \\
\hline BU70 & 5 & 228 & 0 & 0 & 2 & 2 & 0 & 0 & 2 & 2 & 2 & 2 & 4 & 0.0066 & 0.0015 & 0.0506 & 0.0059 & 62 & 0 & 1 & 1 & 0.0069 \\
\hline BU7 I & 9 & 573 & 0 & 0 & 6 & 6 & 1 & I & 2 & 4 & 8 & 2 & 10 & 0.0044 & 0.0005 & 0.0615 & 0.0045 & 98 & 1 & 0 & 1 & 0.0051 \\
\hline BU72 & 20 & 354 & 2 & 1 & 2 & 5 & 2 & 1 & 1 & 4 & 3 & 6 & 9 & 0.0082 & 0.0062 & 0.0368 & 0.0220 & 195 & 1 & 1 & 2 & 0.0052 \\
\hline BU73 & 5 & 277 & 0 & 0 & 0 & 0 & 1 & 2 & 0 & 3 & 0 & 3 & 3 & 0.0039 & 0.0036 & 0.0000 & 0.0135 & 0 & 0 & 0 & 0 & 0.0000 \\
\hline BU76 & 15 & 330 & 0 & 0 & 7 & 7 & 1 & 1 & 1 & 3 & 9 & 1 & 10 & 0.0087 & 0.0008 & 0.1104 & 0.0041 & 154 & 3 & 3 & 6 & 0.0095 \\
\hline BU77 & 18 & 261 & 3 & 0 & 1 & 4 & 1 & 2 & 0 & 3 & 6 & 1 & 7 & 0.0125 & 0.0136 & 0.0166 & 0.0298 & 198 & 9 & 7 & 16 & 0.0345 \\
\hline BU82 & 13 & 228 & 0 & 0 & 2 & 2 & 0 & 2 & 0 & 2 & 2 & 2 & 4 & 0.0059 & 0.0025 & 0.0402 & 0.0112 & 88 & 2 & 2 & 4 & 0.0156 \\
\hline BU85 & 14 & 299 & 2 & 1 & 8 & 11 & 0 & 0 & 1 & 1 & 11 & 1 & 12 & 0.0108 & 0.0363 & 0.1155 & 0.0033 & 121 & 2 & 0 & 2 & 0.0087 \\
\hline BU88 & 16 & 441 & 2 & 0 & 12 & 14 & 0 & 0 & 2 & 2 & 16 & 0 & 16 & 0.0135 & 0.0000 & 0.1601 & 0.0000 & 212 & 9 & 4 & 13 & 0.0179 \\
\hline BU90 & 4 & 0 & 0 & 0 & 0 & 0 & 0 & 0 & 0 & 0 & 0 & 0 & 0 & 0.0000 & 0.0000 & 0.0000 & 0.0000 & 261 & 1 & 2 & 3 & 0.0021 \\
\hline BU92 & 11 & 345 & 3 & 1 & 3 & 7 & I & I & 1 & 3 & 5 & 5 & 10 & 0.0075 & 0.0031 & 0.0650 & 0.0186 & 110 & 5 & 3 & 8 & 0.0226 \\
\hline BU93 & 8 & 510 & 0 & 0 & 5 & 5 & 0 & 0 & 3 & 3 & 7 & I & 8 & 0.0035 & 0.0004 & 0.0626 & 0.0025 & 137 & 0 & 2 & 2 & 0.0023 \\
\hline BU98 & 4 & 369 & 0 & 0 & 5 & 5 & 0 & 0 & 2 & 2 & 7 & 0 & 7 & 0.0101 & 0.0000 & 0.0843 & 0.0000 & 158 & 2 & 6 & 8 & 0.0257 \\
\hline BU883 & 21 & 354 & I & 0 & 5 & 6 & 2 & 1 & 2 & 5 & 7 & 4 & 11 & 0.0120 & 0.0052 & 0.0913 & 0.0145 & 188 & 8 & 3 & 11 & 0.0189 \\
\hline BU897 & 19 & 303 & 0 & 0 & 2 & 2 & 3 & 1 & 2 & 6 & 3 & 5 & 8 & 0.0080 & 0.0078 & 0.0458 & 0.0210 & 167 & 4 & 3 & 7 & 0.0180 \\
\hline BU90I & 12 & 231 & 0 & 0 & 3 & 3 & 0 & 0 & 0 & 0 & 3 & 0 & 3 & 0.0035 & 0.0000 & 0.0552 & 0.0000 & 229 & 2 & 2 & 4 & 0.0065 \\
\hline BU973 & 5 & 471 & 1 & 1 & 0 & 2 & 0 & 0 & 0 & 0 & 2 & 0 & 2 & 0.0015 & 0.0019 & 0.0000 & 0.0054 & 67 & I & 0 & 1 & 0.0028 \\
\hline BU974 & 3 & 459 & 0 & 0 & 2 & 2 & 0 & 0 & 1 & 1 & 3 & 0 & 3 & 0.0036 & 0.0000 & 0.0265 & 0.0000 & 52 & 1 & 0 & 1 & 0.0096 \\
\hline BU982 & 4 & 240 & 0 & 1 & 1 & 2 & 0 & 0 & 0 & 0 & I & 1 & 2 & 0.0030 & 0.0016 & 0.0190 & 0.0053 & 51 & 1 & 0 & 1 & 0.0107 \\
\hline BU996 & 18 & 543 & 4 & 0 & 2 & 6 & I & I & 1 & 3 & 6 & 3 & 9 & 0.0073 & 0.0019 & 0.0518 & 0.0070 & 87 & 6 & 6 & 12 & 0.0312 \\
\hline$K d r$ & 13 & 201 & 0 & 0 & 0 & 0 & 1 & 1 & 0 & 2 & 0 & 2 & 2 & 0.0020 & 0.0026 & 0.0000 & 0.0127 & 501 & 2 & 5 & 7 & 0.0039 \\
\hline Total & & $|467|$ & 45 & 17 & 139 & 201 & 25 & 23 & 54 & 102 & 206 & 97 & 303 & & & & & 5876 & 106 & 85 & 191 & \\
\hline Average & & & & & & & & & & & & & & 0.0072 & $0.004 I$ & 0.0537 & 0.0097 & & & & & 0.0123 \\
\hline
\end{tabular}

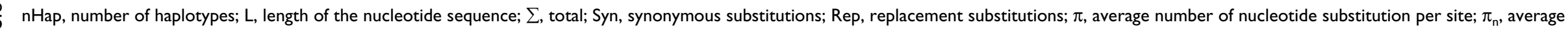
- number of non-synonymous nucleotide substitution per site; $K_{s}$, average number of nucleotide substitution per synonymous site; $K_{a}$, per non-synonymous site; $T_{s}$, transitions; $T_{v}$, transversions. 
sions and there is a stronger selection against replacement substitutions than against synonymous, leading to an increase of the relative frequency of transitions [13]. For fourfold degenerate codons, selection should be neutral, since no amino acid change is induced by a nucleotide substitution at the third position, and each of the 4 codons will produce the same amino acid. We tested this hypothesis by comparing the proportions of transversions at fourfold degenerate codon positions and at non-coding positions for all the 50 genes (Table 2 ). The result shows that there is no significant difference between the frequency of transversions at fourfold degenerate codon positions (36.8\%) and at non-coding regions (44.5\%) $\left(\chi^{2}\right.$ $=2.55 P=0.11)$, while this difference is significant between coding and non-coding regions $\left(\chi^{2}=5.33 ; P=\right.$ $0.021)$. The fact that fourfold degenerate sites have a similar ratio of transitions/tranversions to non-coding regions is consistent with an hypothesis that the structure of the genetic code and selection against replacement polymorphisms accounts for the preponderance of transition substitutions in coding regions.

Five insertion/deletion polymorphisms (indels) were observed in four genes ranging from 1 to $4 \mathrm{bp}$ in coding, intronic and 5'UTR regions (Table 3). Two indels of 2 and 4 bp were observed in the BU10 intron. The frequency of indels $(8 \%$ for $4 / 50)$ is lower than that reported in $A e$ aegypti of $24 \%$ [10] or $25 \%$ in An. gambiae [19]. Only one indel, in the BU93 gene, was located in a coding region. This indel was a triplet that did not cause a frame shift. The four indels identified can serve as molecular makers for mapping studies.

Approximately 2/3 (206) of the 303 cSNPs were synonymous substitutions (no modification in amino acid) while around 1/3 (97) were non-synonymous or replace-

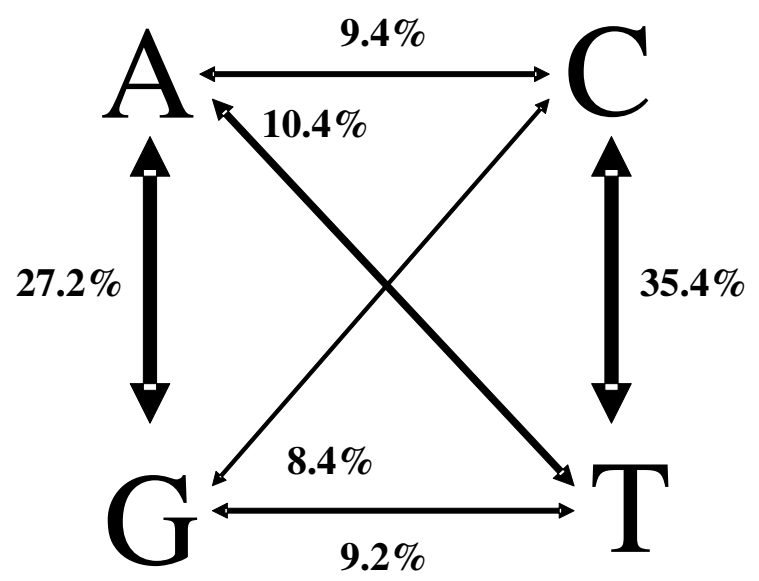

Figure I

Distribution of transitions and transversions among SNPs. ment SNPs leading to a change of amino acid. As approximately two-thirds of random coding substitutions change an amino acid, the fact that only $1 / 3$ of cSNPs are non-synonymous implies strong selection against changes that alter amino acid. This ratio of synonymous and replacement cSNPs is similar to that observed in $A n$. gambiae [19] and Ae. aegypti [10].

\section{Genetic diversity}

We estimated the nucleotide diversity for each of the 50 genes in coding and non-coding regions (Table 1). The average nucleotide diversity per gene in coding regions was $7.2 \times 10^{-3}$ or around 1 SNP every 138 bp similar to that observed in An. gambiae (1 SNPs every $125 \mathrm{bp}$ ) [19] but much higher than the frequency of $1 \mathrm{SNP} / \mathrm{kb}$ observed in humans [20]. SNPs were observed in non-coding regions at a frequency of 1 SNP per $100 \mathrm{bp}$, corresponding to $\pi=10 \times 10^{-3}$. Figure 2 shows that there is a positive correlation in the level of polymorphism between coding and non coding regions of An. funestus genome within a gene $(\mathrm{r}=0.48, P<0.01)$. This positive correlation may be the consequence of many factors notably the correlated genealogies existing between coding regions and their surrounding non-coding regions. This correlation may also be strengthened by the presence of indirect selection (hitchhiking or background selection) and probably by variable recombination rate, as it is the case in Drosophila [21]. Mutational effect of recombination or biased gene conversion can also operate, but this needs to be confirmed as even in Drosophila, the effect of biased gene conversion is only suspected but unwarranted $[22,23]$. The average nucleotide diversity in non-coding DNA (0.010) was lower than in synonymous sites of the coding regions (0.0207), $P<0.01$. This pattern was also observed in $A n$ gambiae, Ae aegypti and Drosophila species $[10,13,19]$. This is an indication that non-coding regions are under greater purifying selection than synonymous sites within coding regions. This is not surprising, given that non-coding regions may be involved in gene regulation. The non-coding 5 '-flanking sequence of a gene may contain regulatory elements such as the promoter that control the expression of that gene, and single-base mutations can affect essential structures for splicing and processing [24].

Nucleotide diversity varies greatly from one gene to another (Table 1) and this is likely related to individual gene function and potentially to differences in selective constraints. However, non-synonymous diversities need to be compared in order to definitely estimate the influence of differences in selective constraints. Among the most polymorphic genes sequenced were cytochrome P450 genes, lysozyme, translation initiation factor and ubiquitin conjugating genes. The non-synonymous nucleotide diversity of these genes varied from 14 to $36.3 \times 10^{-}$ ${ }^{3}$. Most of these genes are involved in specific mechanisms that evolve very rapidly, such as detoxification of xenobi- 
Table 2: Transition $\left(T_{s}\right)$ and transversion (Tv) polymorphisms for different classes of DNA

\begin{tabular}{|c|c|c|c|c|c|c|}
\hline & \multicolumn{3}{|c|}{ Polymorphism } & \multicolumn{3}{|c|}{ Probability } \\
\hline & $\mathbf{T}_{\mathrm{s}}$ & $\mathbf{T}_{\mathbf{v}}$ & $\% \mathbf{T}_{\mathbf{v}}$ & Coding Region & $3^{\text {rd }}$ coding position & Fourfold \\
\hline Non coding regions & 106 & 85 & 44.5 & $P=0.021$ & $P=0.0$ & $P=0.11$ \\
\hline Coding regions (Cd-R) & 201 & 102 & 33.6 & & $P=0.204$ & $P=0.507$ \\
\hline Third coding position & 139 & 54 & 27.9 & & & $P=0.047$ \\
\hline Fourfold degenerate sites & 60 & 35 & 36.8 & & & \\
\hline
\end{tabular}

otics for cytochrome P450s or defense mechanisms against bacteria like lysozyme. For example, P450s present a high level of redundancy with less genetic constraints and therefore more polymorphism. In contrast some genes showed very low level of variation particularly those involved in transcriptional or translational regulation (BU973 and BU25, BU93) or in signaling processes (BU01, BU08, BU13). Examples of selective constraints have been observed as well in Drosophila spp. where substitution rate between conservative genes and fast evolving genes differ by around 10-fold [25]. Nucleotide diversity was not statistically different between laboratory strains and field collected mosquitoes $\left(7.4 \times 10^{-3}\right.$ and $6.9 \times 10^{-3}$; $P=0.21$ by Student's t-test), despite an apparent low level of heterozygosity (fewer heterozygote SNPs) observed in the two laboratory strains compared to the field sample. This result could be due to the fact that FUMOZ and FANG (the two laboratory strains used in this study), were only recently colonized in laboratory and therefore still largely retain the polymorphism of natural populations of An. funestus.

The ratio of synonymous to non-synonymous changes $(\mathrm{Ka} / \mathrm{Ks})$ gives an indication of the magnitude of the purifying selection against deleterious mutations in a species. The rate of non-synonymous nucleotide substitution per non-synonymous site $(\mathrm{Ka})$ is generally expected to be much lower than the rate of synonymous substitution per synonymous site (Ks), because random amino acid changes are usually deleterious, whereas synonymous changes are likely to be neutral or nearly so [26]. Thus, the expectation is $\mathrm{Ka}<<\mathrm{Ks}$, except when positive selection is involved favouring particular amino acid replacements, in which case Ka will increase. For An. funestus the Ka/Ks ratio was equal to 0.181 and is similar to the ratio of 0.192 observed in An. gambiae [19] or 0.204 in Ae. aegypti [10] but, higher than the ratio of 0.115 reported in $D$. melanogaster [13]. This result indicates that the purifying selection against deleterious mutations is acting in An. funestus. Indeed species with large effective population size such Drosophila or Anopheles species are generally more effective at purging deleterious mutations [26].

\section{Clustering pattern of the SNPs}

We analyzed the distribution of SNPs identified in this study. We found 16 clusters of two directly neighboring SNPs, one cluster of 3 consecutive SNPs and 13 clusters of two SNPs separated by just 1 bp. For some SNP genotyping methods based on allele-specific amplification, ligation or single base extension principles for which primers need to be designed immediately adjacent to the SNP, it is important that the SNPs are not too close together to prevent primer designing. The presence of a polymorphism within approximately $20 \mathrm{bp}$ will limit the possibilities for designing a robust primer. Most of the 494 SNPs identified in this study do not have a SNP within 20 bp on either or one side thus, and should be easily genotyped by one of these methods.

\section{Genomic position of the SNPs}

Among the 50 genes amplified for SNP detection in this study, 45 are already physically mapped to the An. funestus genome by in situ hybridization [27], and the remaining 5 genes were genetically located to their respective chromosome by linkage mapping [7]. Overall, 29 SNPs were located on the $\mathrm{X}$ chromosome, 334 on chromosome 2 and 131 on chromosome 3 . The higher number of SNPs observed on chromosome 2 is also a consequence of the fact that most of the studied genes are located on that chromosome. Table 4 gives the chromosomal location of the 50 genes across the genome of An. funestus.

\section{Polymorphism reliability}

To assess the validity of the SNPs identified in this study, 30 SNPs were tested for segregation in isofemale lines. These SNPs were tested using different methods (pyrose-

Table 3: Indel polymorphism

\begin{tabular}{lllll}
\hline & & \multicolumn{3}{c}{ Non coding region } \\
\hline Gene & Coding region & Introns & 5' UTR & 3'UTR \\
\hline $6 P 5$ & & $4 \mathrm{bp}$ & \\
BU10 & & $2 \mathrm{bp}, 4 \mathrm{bp}$ & \\
BU66 & & & I bp \\
BU93 & $3 \mathrm{bP}$ & & \\
\hline
\end{tabular}




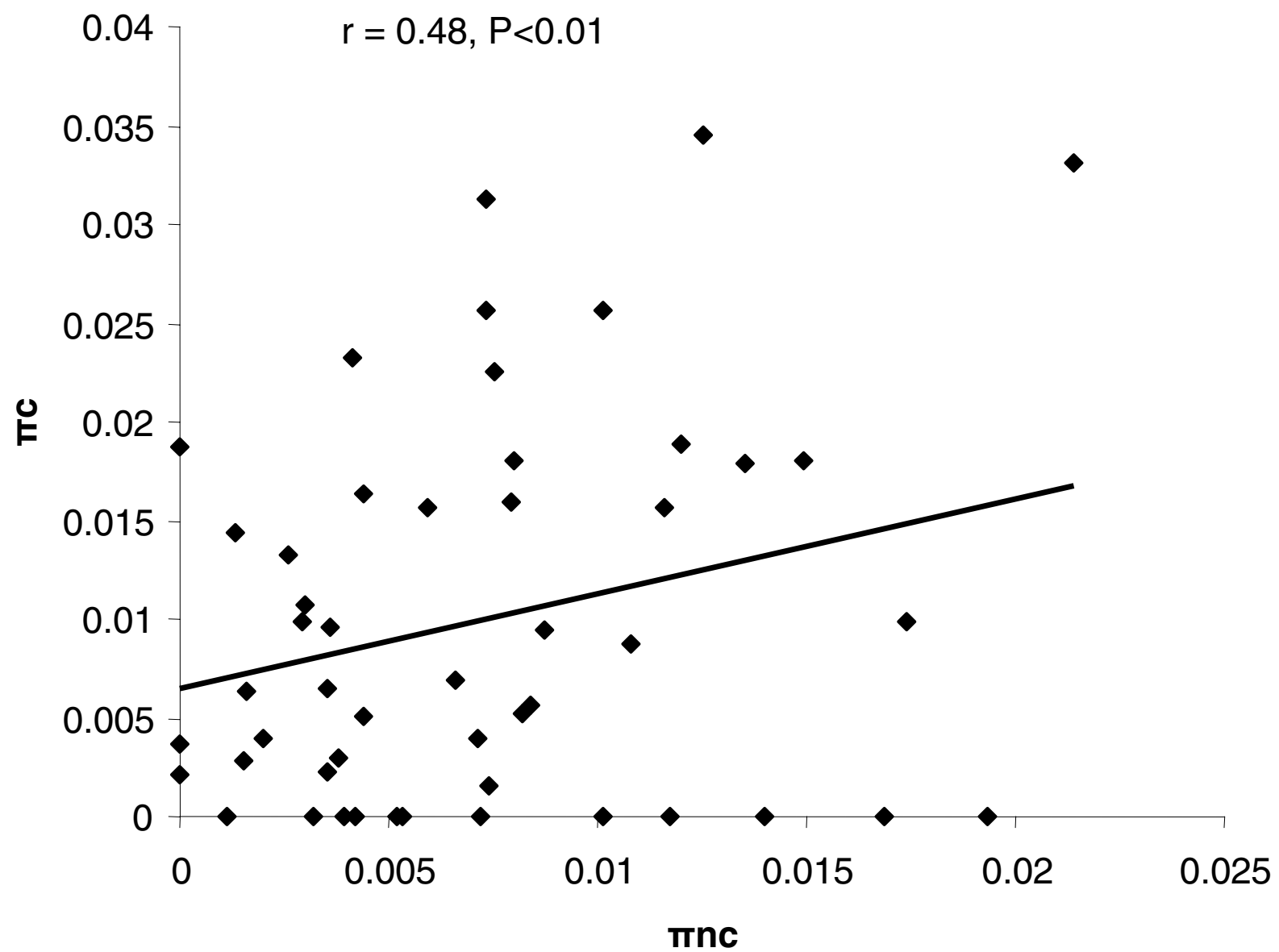

\section{Figure 2}

Correlation of nucleotide diversity in coding $\left(\pi_{\mathrm{c}}\right)$ and non-coding regions $\left(\pi_{\mathrm{nc}}\right) \pi_{\mathrm{c}}$ : nucleotide diversity of coding region, $\pi_{\mathrm{nc}}$ : nucleotide diversity of non-coding region.

quencing, HOLA, SBE and AS-PCR) [7,28]. The Mendelian segregation ratio of each of these SNP loci at $\mathrm{F}_{0}, \mathrm{~F}_{1}$ and $\mathrm{F}_{2}$ generations was examined in four families from reciprocal crosses between a pyrethroid resistant strain (FUMOZ-R) and a susceptible strain (FANG). Homozygous and heterozygous genotypes for each of these SNPs were observed. Importantly, the expected Mendelian ratio of 1:2:1 was respected in 27 of these 30 SNPs [7], confirming the polymorphism observed at these different positions. We can conclude from this result that the SNPs described in this study are then likely to be true polymorphisms rather than sequence artifacts and our scoring results indicate that they are suitable for use as genetic markers.

\section{Relevance of the SNPs}

The set of SNPs identified in this study provide a very useful tool for future genetic studies in An. funestus. These markers are of immediate use for association and QTL mapping studies. Some of these SNPs have been used for linkage mapping and identification of QTL involved in pyrethroid resistance in An. funestus [7]. This set of SNPs can be used as tools for population genetic studies in An. funestus. Genotyping large number of SNP markers will facilitate the study of genetic structure of natural populations and provide independent estimates of gene flow. It may provide additional markers to study the speciation process observed between the Folonzo and Kiribina chromosomal forms of An. funestus [29]. These markers may also be invaluable in monitoring insecticide resistance genes or genes involved in vector competence.

\section{Conclusion}

Through the sequencing of DNA fragments from 50 genes of An. funestus, we identified a set of 494 SNP markers and studied the pattern of genetic variability in this species. The distribution of SNPs in An. funestus was not neutral but under the influence of regional factors such as recom- 
bination, the degeneracy of the genetic code and selective constraints for gene conservation. The SNP markers described constitutes an important resource for more genetic studies in this important malaria vector.

\section{Methods}

Mosquito samples used for polymorphism discovery

We used adult female specimens of An. funestus from two laboratory strains, FANG and FUMOZ-R (seven specimens for each strain) as well as seven field specimens. FANG is a pyrethroid susceptible strain from Calueque, southern Angola and FUMOZ-R is a pyrethroid resistant strain from southern Mozambique [1]. Field specimens of An. funestus were collected from Kela village in Chikwawa district in southern Malawi.

\section{Selection of gene sequences for SNP identification}

Target genes were selected among cytochrome P450 genes for their putative involvement in insecticide resistance [30] or among genes of a broad range of functions that had been physically mapped to An. funestus polytene chromosomes [27] (see Table 4; Figure 3). They were also chosen to be distributed across the genome of An. funestus. The sequences of the physically mapped cDNAs were retrieved from Genbank. Determination of coding sequence, UTRs and intronic regions were done using the BLAST procedure through NCBI.

\section{Gene amplification and sequencing}

Genomic DNA was extracted using the LIVAK method as described previously [31]. Primers were designed using Primer3 software [32] to flank putative intron sites to maximize the chance of SNP identification. Genomic DNA from 21 individuals ( 7 from FUMOZ-R, 7 from FANG and 7 from Kela) was amplified for each gene. PCR was performed with $10 \mathrm{ng}$ of genomic DNA in a final volume of $25 \mu \mathrm{l}$ containing, $2.5 \mu \mathrm{l}$ Taq buffer, $0.2 \mathrm{mM}$ of dNTPs, 10 pmoles of each primer, $2.5 \mathrm{mM}$ of $\mathrm{MgCl} 2,0.2$ unit of Taq polymerase (Qiagen). Amplification was performed with the following conditions: 1 cycle at $94^{\circ} \mathrm{C}$ for $3 \mathrm{~min} ; 35$ cycles of $94^{\circ} \mathrm{C}$ for $30 \mathrm{~s}, 57^{\circ} \mathrm{C}$ for $30 \mathrm{~s}$ and elongation at $72^{\circ} \mathrm{C}$ for $30 \mathrm{~s}$; followed by 1 cycle at $72{ }^{\circ} \mathrm{C}$ for 10 min. The annealing temperature was optimized for each primer pair and varied between $53^{\circ} \mathrm{C}$ to $62^{\circ} \mathrm{C}$.

PCR products were purified using the QIaquick PCR purification kit (Qiagen) and directly sequenced on both strands using a Beckman CEQ 8000 automatic sequencer.

\section{Sequence analysis and SNP detection}

SNPs were detected as sequence differences in multiple alignments using Clustalw [33]. Electrophoregrams were visually inspected using BioEdit and heterozygotes were identified [12]. SNPs were identified as transitions or transversions in coding and non-coding regions. SNPs located within coding regions were classified as synonymous or non-synonymous and their codon position determined. Nucleotide diversity analyses were performed using DnaSP 4.0 [34]. The average number of nucleotide substitutions per site between two sequences, $\pi$ was calculated for each gene as well as the haplotype diversity. The average number of synonymous substitutions per synonymous site (Ks) and non-synonymous substitutions per non-synonymous site $(\mathrm{Ka})$ was computed according to [35].

\section{SNP validation}

Many of the SNPs discovered in this study were validated by different methods. As a part of an effort to construct a genetic map and to identify QTL involved in pyrethroid resistance, 30 SNP loci were genotyped in several families generated from a cross between FANG and FUMOZ-R strains of An. funestus. These SNPs were scored using a HOLA (Hot Oligonucleotides Ligation Assay) method [36], single base extension (SBE) using Beckman CEQ8000 and a pyrosequencing method [7].

\section{Authors' contributions}

CSW (corresponding author) carried out the experiments; analyzed the data and wrote the manuscript. JH is the PI of the program that funded the work and contributed to the critical review of the draft manuscript. HR contributed to the design of the study and critical review of the draft manuscript. All authors read and approved the final manuscript. 
Table 4: Characteristics of genes amplified for SNP detection

\begin{tabular}{|c|c|c|c|c|c|c|c|}
\hline Genes & $\begin{array}{l}\text { Chromosomal } \\
\text { Location }\end{array}$ & Accession no. & Function & Forward primer & Reverse primer & Product length & No of SNPs \\
\hline $4 G 2 I$ & $x$ & $\underline{\text { AY } 648704}$ & Cytochrome P450 & GGCGATAGCAAACGTAAAGC & CGCGGTAAACGGAATATAGC & 303 & 2 \\
\hline $9 K I$ & $x$ & $\underline{\text { AY987362 }}$ & Cytochrome P450 & GTACGAGCTGGCCGTTAATC & ССTTTCTGTAGCTGCACCTTG & 243 & 9 \\
\hline $4 J 12$ & $3 R$ & $\underline{\text { AY } 648706}$ & Cytochrome P450 & CCAACAAATCAGTTCATCAGC & TTGTAAAAGTGCTTAAAATG & 270 & 9 \\
\hline 6P9 & $2 R: 9 A-12 C$ & $\underline{\text { AY729661 }}$ & Cytochrome P450 & GCGCCTTAGACAAGAGATCA & AAGGGATGTCGCTTCTTCTC & 350 & 8 \\
\hline 6P4 & $2 R: 9 A-12 C$ & $\underline{\text { AY987359 }}$ & Cytochrome P450 & GTACGAGACTGGCAAAGAAT & AAGGAAGACGTATGGATGG & 430 & 13 \\
\hline $6 P 5$ & $2 R: 9 A-12 C$ & $\underline{\text { AY } 987360}$ & Cytochrome P450 & CTGGCTTTGAAACTTCCTC & AGATACACGTAGGGATGTCG & 550 & 3 \\
\hline $6 Z 1$ & 2L: 25A-27D & & Cytochrome P450 & ACGATCCGTTCCGGGTAG & GCTAGCGCAGGATACATTCG & 550 & 12 \\
\hline $6 Z 3$ & 2L: 25A-27D & & Cytochrome P450 & GACGATCCGTTCCTGAAGAC & ATCGGTAAGCCCGGATATTT & 550 & 20 \\
\hline $9 J 12$ & $3 L$ & $\underline{\text { AY729663 }}$ & Cytochrome P450 & TACCGGTGTGCAGCTTGA & CTTTGGCGCGAAGGTAAA & 194 & 5 \\
\hline $9 J 14$ & $3 \mathrm{~L}$ & $\underline{\text { AY729665 }}$ & Cytochrome P450 & CGGACAACGTATGATCGATTT & TTTGGCTTGCATTAAAAGGTG & 214 & 5 \\
\hline BUOI & $X: 2 B$ & $\underline{B \cup 039001}$ & $\begin{array}{l}\text { type II transforming growth factor-beta } \\
\text { receptor }\end{array}$ & GTGTGTTTGCTTGGGTGTTG & GGCATCGGTAATCAGGATGT & 525 & I \\
\hline BU08 & $2 \mathrm{R}: 7 \mathrm{C}-10 \mathrm{~B}$ & $\underline{B \cup 038908}$ & rhodopsin & CATTTGTGGAACCCCATTTC & GGTCATTGGTTTACCCGAGA & 500 & 7 \\
\hline Ache & $2 R: 9 C-12 C$ & DO534435 & Acetylcholinesterase & GGGTACGGGACAACATTCAC & CGTTAACGTACGGGTCGAGT & 1050 & 15 \\
\hline BUIO & $2 \mathrm{~L}: 28 \mathrm{~A}$ & $\underline{B \cup 039010}$ & Cyt-c-p-PI & AAGCACAGTTAAACCTTTCG & ACCTAGCCCAATCTCTGTCT & 650 & 10 \\
\hline BUII & 3L:43B & $\underline{B \cup 038911}$ & protein transporter & ATCTGCTTGCGCTAGATCGT & ATCGCCAAATTTCATCTTCG & & 2 \\
\hline BUI2 & $2 R: 7 B$ & $\underline{B \cup 038912}$ & Alpha tubilin & AAGCTCGAGTTCGCCATCTA & СТCСAATCCTTTCCGACGTA & 800 & 5 \\
\hline BUI3 & $2 \mathrm{R}: 15 \mathrm{C}$ & $\underline{B \cup 038913}$ & signal sequence receptor & ACCCTGAGAAATCGTAACAA & CCGATAGTTGAGAGCAATGT & 630 & 10 \\
\hline BUI9 & $2 R: 12 B$ & $\underline{B \cup 038919}$ & Chitinase & CTGTTGCTGCTGCTACATAC & CCGGTCACGTACAAATAGTC & 670 & 10 \\
\hline BU02I & $3 \mathrm{~L}: 38 \mathrm{C}-40 \mathrm{~B}$ & $\underline{B \cup 039021}$ & Tubilin beta- 3 chain & GAGTTGGTTGATGCCGTGTT & CGTCCGGAAACAAATATCGT & 400 & 8 \\
\hline BU2I & $X: 3 A$ & $\underline{B \cup 038921}$ & $\begin{array}{l}\text { Phosphoribosylaminoimida-zole } \\
\text { carboxylase }\end{array}$ & TTTCAAGGTGAACGGTGTGA & CCATCAAGATGACGACCAGA & 475 & II \\
\hline BU25 & $2 \mathrm{R} I 2 \mathrm{~B}$ & $\underline{B \cup 038925}$ & ferritin heavy chain-like protein & GCGTAAAGCTGTCGTCCTTC & ATTCCCCCGTCAGGTAGTCT & 1200 & 2 \\
\hline BU29 & $2 \mathrm{~L}: 27 \mathrm{~B}$ & BU038929 & sensory appendage protein & CACCAAGTACGATGGTGTCG & AGGCACTTGGTTTTGCAGTT & 410 & 6 \\
\hline BU34 & $X: I C$ & BU038934 & NADH dehydrogenase & GGCAGGTAGCAGCAGTTTTC & CAGTACCAACCGCAACACAC & 400 & 6 \\
\hline BU35 & $2 \mathrm{R} I 2 \mathrm{~B}$ & $\underline{B \cup 038935}$ & CG6846 gene product & TTCAGCAAACACGTTTCGTC & ACTTGCCCTTGTCCTTGTTG & 400 & 9 \\
\hline BU40 & $2 R: 14 B$ & $\underline{B \cup 038940}$ & Glutathion peroxydase & AGGCAAAATCAATTTTTTGAA & CGTAACAATTTCTCGACCAT & 1150 & 10 \\
\hline BU56 & $2 R: 7 B$ & $\underline{B \cup 038956}$ & novel An. gambiae salivary protein & AATCTAGAAGCTGCGCCAGA & AATTCTAGGACGGCGATTCC & & 13 \\
\hline
\end{tabular}


ip Table 4: Characteristics of genes amplified for SNP detection (Continued)

\begin{tabular}{|c|c|c|c|c|c|c|c|}
\hline BU58 & $2 R: 12 D$ & BU038958 & translation initiation factor & ACTTCCACGCCCAGTGTATC & CGTGCAGAGTTCGAAAACAA & 650 & 5 \\
\hline BU62 & $2 \mathrm{~L}: 23 \mathrm{~A}$ & $\underline{B \cup 038962}$ & $\begin{array}{l}\text { cAMP responsive element binding } \\
\text { protein }\end{array}$ & CAATCGGAGCGTAAGGAAAG & CGTTCTCCCGCAAAAACTAA & 475 & 13 \\
\hline BU66 & $3 R: 30 A$ & $\underline{B \cup 038966}$ & Lysozyme & TAGCTCATAGTGGCGGTTAT & ACTACAACATGTCGTGCAAA & 650 & 22 \\
\hline BU70 & $2 \mathrm{R}: 7 \mathrm{C}$ & $\underline{B \cup 038970}$ & Ubiquitin fusion 80 & GTGGACTCCGTACCTGGTCA & CTGTAGAATTACAGGAGGGCGTA & & 5 \\
\hline BU7I & $3 L: 39 A$ & BU038971 & $\begin{array}{l}\text { structural protein of peritrophic } \\
\text { membrane }\end{array}$ & GGGAAGTCGGTGTAGGGAAT & ACGTTTGGGTCAGGTAGTCG & 750 & II \\
\hline BU72 & $2 R: 12 B$ & BU038972 & RHO small monomeric GTPase & GATGAAGCTGCCAAAGATCC & TGCCTCGTCGAAAACTTCTT & 900 & I I \\
\hline BU73 & $2 R: 7 A$ & $\underline{\mathrm{B} \cup 038873}$ & actin binding & AGTAAGAAACGAACGCAAAG & CGGAAAAGTTGGAATGTAAC & 430 & 3 \\
\hline BU76 & $2 R: 10 B$ & $\underline{B \cup 038976}$ & translation initiation factor & TGCCTACGAACGACGTAATG & GGCTCGTAGCTGGTCACTTC & 500 & 16 \\
\hline BU77 & $2 \mathrm{R}: 10 \mathrm{C}$ & $\underline{B \cup 038877}$ & ubiquitin conjugating enzyme & CAACACACTAGCCAGCAAGG & TTTGGTTCGGCCAACATACT & 408 & 23 \\
\hline BU82 & $2 R: 14 D$ & BU038882 & Unknown & AGGGCGGTACAACAAAATCT & GCATCGGAGCGTTTCCTA & 400 & 8 \\
\hline BU85 & $2 \mathrm{R}: 12 \mathrm{E}$ & $\underline{B \cup 038885}$ & phosphoglycerate mutase & AAAAAGAATGGCCGGAAAGT & CTCATCGCCCAGAATTTCAT & 800 & 14 \\
\hline BU88 & $2 R: I I B$ & BU038988 & translation initiation factor & GTGGCCTCCCACTTTGTTAG & TACCGGATACGGTTGACGAT & 800 & 29 \\
\hline BU90 & $3 R: 35 B$ & $\underline{B \cup 038990}$ & gustatory receptor & GGGACATCATCATCATCGAC & TTTCGCTTCTCGCGTTAAAT & 300 & 3 \\
\hline BU92 & $3 L: 39 A$ & BU038892 & Microtubule binding & CATGCGACCGAAGAGAAGTT & ATCCTGATTCTGGCTCATGG & 550 & 18 \\
\hline BU93 & $2 \mathrm{R}: 7 \mathrm{C}-10 \mathrm{C}$ & $\underline{B \cup 038893}$ & prefoldin subunit 2 & CACCGGAAACTCGGCTATTA & TATCGGTTCCATCCGAAAAG & 550 & 10 \\
\hline BU98 & $3 L: 46 B$ & $\underline{B \cup 038898}$ & CG7630 gene product & TGCGTCACCCGTTACAAATA & ACGTGTACGCTTTCCACCTC & 550 & 15 \\
\hline BU883 & $3 R: 32 B$ & $\underline{B \cup 038883}$ & peritrophin & TTCGTGACACAGTTATACGC & GCACACTTCAGACTTCCTGT & 650 & 22 \\
\hline BU897 & $3 R: 36 C$ & $\underline{B U 038897}$ & NADH dehydrogenase (ubiquinone) & GGGAATTCCGTGATTTTT & GGCAGAAATATCCATAATCG & 700 & 15 \\
\hline BU90I & $2 \mathrm{~L}: 20 \mathrm{C}$ & BU03890I & CGI8397 gene product & AAAGACACTCCCGCATTACG & CTCGTGTCTGTTTGGCTTGA & 480 & 7 \\
\hline BU973 & $3 \mathrm{R}: 36 \mathrm{~F}$ & $\underline{B \cup 038973}$ & polyA-binding protein II & AGTAAGAAACGAACGCAAAG & CGGAAAAGTTGGAATGTAAC & 630 & 3 \\
\hline BU974 & $3 \mathrm{~L}: 40 \mathrm{~A}$ & BU038974 & serine-type peptidase & ACTGGCGGAGAACGTACAAC & TGCTGCACATTAATCAAAGGTT & & 4 \\
\hline BU982 & $2 R: 12 B$ & BU038982 & ferritin 2 light chain homologue & CTAGTTTCCTGTCGCGTTCC & CATCGTCTCCTCCATTACCG & 400 & 3 \\
\hline BU996 & $2 R: 8 D$ & $\underline{B \cup 038996}$ & $\begin{array}{c}\text { vacuolar hydrogen-transporting } \\
\text { ATPase }\end{array}$ & GTTCGCCTACATGTGCTTCA & ACAAAGGGTGTGCAAAAAGG & 800 & 21 \\
\hline Kdr & 3R: 36A-37E & DQ534436 & Sodium channel gene & TGCAAAATAGAGTCATTGGTGAA & ATCATCTTCATCTTTGC & 1342 & 9 \\
\hline
\end{tabular}




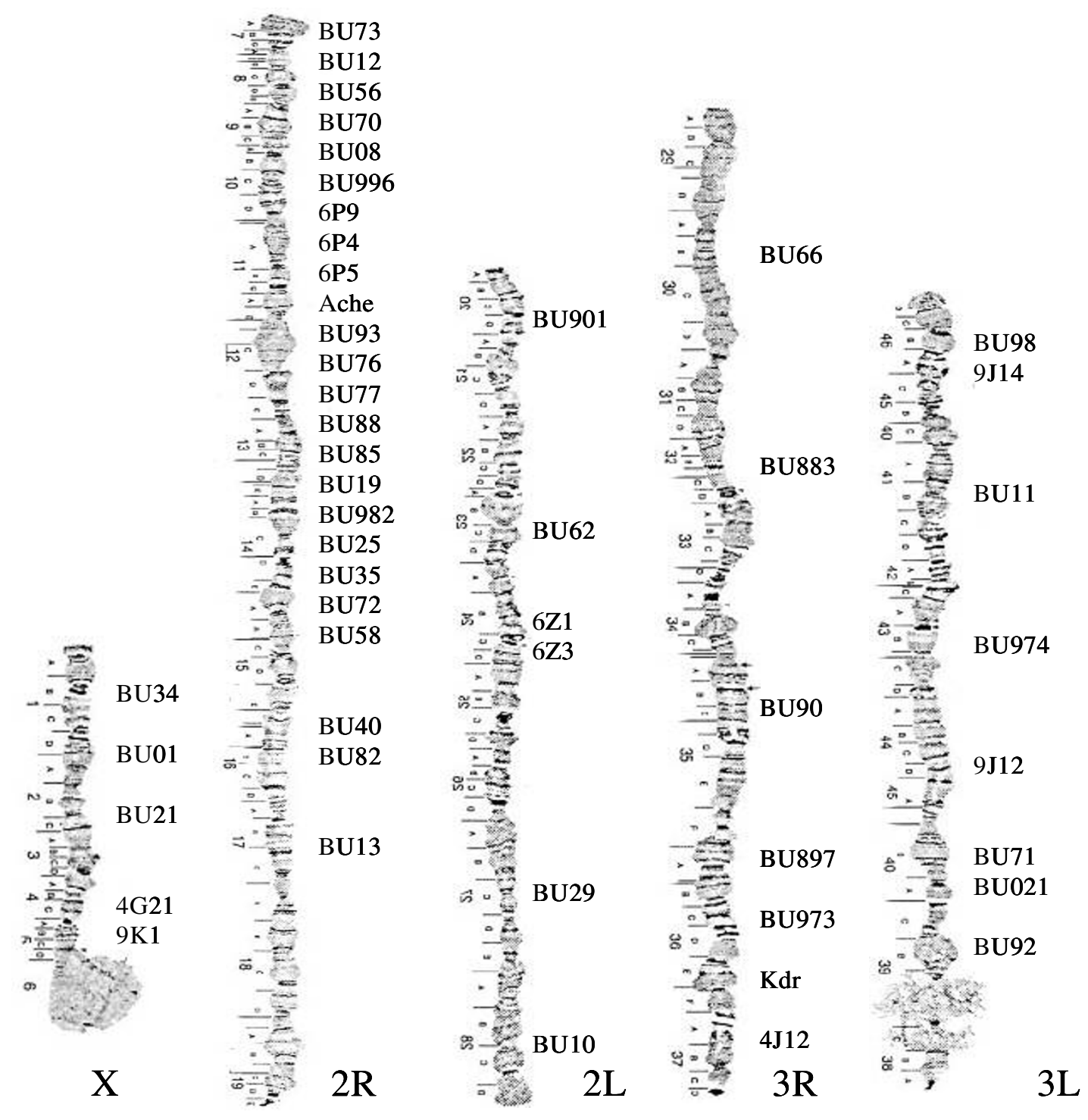

Figure 3

Relative location of studied genes on the An. funestus genome. For definitions of genes, see Table 4. This figure was adapted from [37]. 


\section{Acknowledgements}

This work was supported by the National Institute of Health $(\mathrm{NIH})$ grant IU0I AI05827I-0I. The authors acknowledge Keith Steen for technical help, John Morgan and Maureen Coetzee for providing the An. funestus specimens used in this study. We are grateful to three anonymous reviewers for their helpful comments on this manuscript.

\section{References}

I. Hunt RH, Brooke BD, Pillay C, Koekemoer LL, Coetzee M: Laboratory selection for and characteristics of pyrethroid resistance in the malaria vector Anopheles funestus. Med Vet Entomol 2005, 19(3):27|-275.

2. Sinkins SP, Hackett BJ, Costantini C, Vulule J, Ling YY, Collins FH, Besansky NJ: Isolation of polymorphic microsatellite loci from the malaria vector Anopheles funestus. Mol Ecol 2000, 9(4):490-492.

3. Cohuet A, Simard F, Berthomieu A, Raymond M, Fontenille D, Weill $M$ : Isolation and characterization of microsatellite DNA markers in the malaria vector Anopheles funestus. Molecular Ecology Notes 2002, 2(4):498-500.

4. Cohuet A, Dia I, Simard F, Raymond M, Fontenille D: Population structure of the malaria vector Anopheles funestus in Senegal based on microsatellite and cytogenetic data. Insect $\mathrm{Mol}$ Biol 2004, I3(3):25I-258.

5. Cohuet A, Dia I, Simard F, Raymond M, Rousset F, Antonio-Nkondjio C. Awono-Ambene PH, Wondji CS, Fontenille D: Gene flow between chromosomal forms of the malaria vector Anopheles funestus in Cameroon, Central Africa, and its relevance in malaria fighting. Genetics 2005, I 69(I):30 I-3 I I.

6. Michel AP, Ingrasci MJ, Schemerhorn BJ, Kern M, Le Goff G, Coetzee M, Elissa N, Fontenille D, Vulule J, Lehmann T, Sagnon N, Costantini C, Besansky NJ: Rangewide population genetic structure of the African malaria vector Anopheles funestus. Mol Ecol 2005, I 4( 1 4):4235-4248.

7. Wondji CS, Hunt RH, Pignatelli P, Steen K, Coetzee M, Besansky N, Lobo N, Collins FH, Hemingway J, Ranson $\mathrm{H}$ : An integrated genetic and physical map for the malaria vector Anopheles funestus. Genetics 2005, I7I(4): I779-1787.

8. Cargill M, Altshuler D, Ireland J, Sklar P, Ardlie K, Patil N, Shaw N, Lane CR, Lim EP, Kalyanaraman N, Nemesh J, Ziaugra L, Friedland L, Rolfe A, Warrington J, Lipshutz R, Daley GQ, Lander ES: Characterization of single-nucleotide polymorphisms in coding regions of human genes. Nat Genet 1999, 22(3):231-238.

9. Hoskins RA, Phan AC, Naeemuddin M, Mapa FA, Ruddy DA, Ryan J, Young LM, Wells T, Kopczynski C, Ellis MC: Single nucleotide polymorphism markers for genetic mapping in Drosophila melanogaster. Genome Res 200I, I I(6): I I00-IIII3.

10. Morlais I, Severson DW: Intraspecific DNA variation in nuclear genes of the mosquito Aedes aegypti. Insect Mol Biol 2003, I 2(6):631-639.

II. Wang DG, Fan JB, Siao C), Berno A, Young P, Sapolsky R, Ghandour G, Perkins N, Winchester E, Spencer J, Kruglyak L, Stein L, Hsie L, Topaloglou T, Hubbell E, Robinson E, Mittmann M, Morris MS, Shen N, Kilburn D, Rioux J, Nusbaum C, Rozen S, Hudson TJ, Lipshutz R, Chee M, Lander ES: Large-scale identification, mapping, and genotyping of single-nucleotide polymorphisms in the human genome. Science 1998, 280(5366): I077-1082.

12. Black WC, Baer CF, Antolin MF, DuTeau NM: Population genomics: genome-wide sampling of insect populations. Annu Rev Entomol 200I, 46:44I-469.

13. Moriyama EN, Powell JR: Intraspecific nuclear DNA variation in Drosophila. Mol Biol Evol 1996, I3(I):26I-277.

14. Moriyama EN, Powell JR: Codon usage bias and tRNA abundance in Drosophila. I Mol Evol 1997, 45(5):5 14-523.

I5. Powell JR, Moriyama EN: Evolution of codon usage bias in Drosophila. Proc Natl Acad Sci U S A 1997, 94( I 5):7784-7790.

16. Holt RA, Subramanian GM, Halpern A, Sutton GG, Charlab R, Nusskern DR, Wincker P, Clark AG, Ribeiro JM, Wides R, Salzberg SL, Loftus B, Yandell M, Majoros WH, Rusch DB, Lai Z, Kraft CL, Abril JF, Anthouard V, Arensburger P, Atkinson PW, Baden $\mathrm{H}$, de Berardinis V, Baldwin D, Benes V, Biedler J, Blass C, Bolanos R, Boscus D, Barnstead M, Cai S, Center A, Chaturverdi K, Christophides GK, Chrystal MA, Clamp M, Cravchik A, Curwen V, Dana A, Delcher A, Dew I, Evans CA, Flanigan M, Grundschober-Freimoser A, Friedli L, Gu Z,
Guan P, Guigo R, Hillenmeyer ME, Hladun SL, Hogan JR, Hong YS, Hoover J, Jaillon O, Ke Z, Kodira C, Kokoza E, Koutsos A, Letunic I, Levitsky A, Liang Y, Lin JJ, Lobo NF, Lopez JR, Malek JA, McIntosh TC, Meister S, Miller J, Mobarry C, Mongin E, Murphy SD, O'Brochta DA, Pfannkoch C, Qi R, Regier MA, Remington K, Shao H, Sharakhova MV, Sitter CD, Shetty J, Smith TJ, Strong R, Sun J, Thomasova D, Ton LQ, Topalis P, Tu Z, Unger MF, Walenz B, Wang A, Wang J, Wang M, Wang X, Woodford KJ, Wortman JR, Wu M, Yao A, Zdobnov EM, Zhang H, Zhao Q, Zhao S, Zhu SC, Zhimulev I, Coluzzi M, della Torre A, Roth CW, Louis C, Kalush F, Mural RJ, Myers EW, Adams MD, Smith HO, Broder S, Gardner MJ, Fraser CM, Birney E, Bork P, Brey PT, Venter JC, Weissenbach J, Kafatos FC, Collins FH, Hoffman SL: The genome sequence of the malaria mosquito Anopheles gambiae. Science 2002, 298(559I): I29-149.

17. Holliday R, Grigg GW: DNA methylation and mutation. Mutat Res 1993, 285(I):6I-67.

18. Brookes AJ: The essence of SNPs. Gene 1999, 234(2): I77-186.

19. Morlais I, Poncon N, Simard F, Cohuet A, Fontenille D: Intraspecific nucleotide variation in Anopheles gambiae: new insights into the biology of malaria vectors. Am J Trop Med Hyg 2004, 7 I (6):795-802.

20. Aquadro CF, Bauer DuMont V, Reed FA: Genome-wide variation in the human and fruitfly: a comparison. Curr Opin Genet Dev 200 I, I I (6):627-634

21. Begun DJ, Aquadro CF: Levels of naturally occurring DNA polymorphism correlate with recombination rates in $\mathrm{D}$. melanogaster. Nature 1992, 356(6369):519-520.

22. Kern AD, Begun DJ: Patterns of polymorphism and divergence from noncoding sequences of Drosophila melanogaster and D. simulans: evidence for nonequilibrium processes. Mol Biol Evol 2005, 22(I):51-62.

23. Galtier N, Bazin E, Bierne N: GC-biased segregation of noncoding polymorphisms in Drosophila. Genetics 2006, I 72(I):221-228.

24. Shen LX, Basilion JP, Stanton VP Jr.: Single-nucleotide polymorphisms can cause different structural folds of mRNA. Proc Natl Acad Sci U S A 1999, 96( 14):787|-7876.

25. Schmid KJ, Tautz D: A screen for fast evolving genes from Drosophila. Proc Natl Acad Sci U S A 1997, 94( I 8):9746-9750.

26. Kimura $M$, Takahata N: Selective constraint in protein polymorphism: study of the effectively neutral mutation model by using an improved pseudosampling method. Proc Natl Acad Sci U S A 1983, 80(4): 1048-1052.

27. Sharakhov IV, Serazin AC, Grushko OG, Dana A, Lobo N, Hillenmeyer ME, Westerman R, Romero-Severson J, Costantini C, Sagnon $\mathrm{N}$, Collins FH, Besansky NJ: Inversions and gene order shuffling in Anopheles gambiae and A. funestus. Science 2002, 298(559|): $182-185$

28. Lynd A, Ranson H, McCall PJ, Randle NP, Black WC, Walker ED, Donnelly MJ: A simplified high-throughput method for pyrethroid knock-down resistance (kdr) detection in Anopheles gambiae. Malar J 2005, 4(I): I6.

29. Costantini C, Sagnon N, Ilboudo-Sanogo E, Coluzzi M, Boccolini D Chromosomal and bionomic heterogeneities suggest incipient speciation in Anopheles funestus from Burkina Faso. Parassitologia 1999, 4I(4):595-6II.

30. Amenya DA, Koekemoer LL, Vaughan A, Morgan JC, Brooke BD, Hunt RH, Ranson H, Hemingway J, Coetzee M: Isolation and sequence analysis of $\mathbf{P 4 5 0}$ genes from a pyrethroid resistant colony of the major malaria vector Anopheles funestus. DNA Seq 2005, I 6(6):437-445.

31. Collins FH, Mendez MA, Rasmussen MO, Mehaffey PC, Besansky NJ, Finnerty $V$ : A ribosomal RNA gene probe differentiates member species of the Anopheles gambiae complex. Am J Trop Med Hyg 1987, 37(I):37-4I.

32. Rozen S, Skaletsky H: Primer3 on the WWW for general users and for biologist programmers. Methods Mol Biol 2000, 132:365-386.

33. Thompson JD, Higgins DG, Gibson TJ: CLUSTAL W: improving the sensitivity of progressive multiple sequence alignment through sequence weighting, position-specific gap penalties and weight matrix choice. Nucleic Acids Res 1994, 22(22):4673-4680.

34. Rozas J, Sanchez-DelBarrio JC, Messeguer X, Rozas R: DnaSP, DNA polymorphism analyses by the coalescent and other methods. Bioinformatics 2003, I9( I 8):2496-2497. 
35. Nei M, Gojobori T: Simple methods for estimating the numbers of synonymous and nonsynonymous nucleotide substitutions. Mol Biol Evol I986, 3(5):418-426.

36. Black WC, Gorrochotegui-Escalante N, Duteau NM: Heated oligonucleotide ligation assay (HOLA): an affordable single nucleotide polymorphism assay. J Med Entomol 2006, 43(2):238-247.

37. Sharakhov I, Braginets O, Grushko O, Cohuet A, Guelbeogo WM Boccolini D, Weill M, Costantini C, Sagnon N, Fontenille D, Yan G, Besansky NJ: A microsatellite map of the African human malaria vector Anopheles funestus. J Hered 2004, 95(I):29-34.

Publish with Bio Med Central and every scientist can read your work free of charge

"BioMed Central will be the most significant development for disseminating the results of biomedical research in our lifetime. "

Sir Paul Nurse, Cancer Research UK

Your research papers will be:

- available free of charge to the entire biomedical community

- peer reviewed and published immediately upon acceptance

- cited in PubMed and archived on PubMed Central

- yours - you keep the copyright

Submit your manuscript here:

http://www.biomedcentral.com/info/publishing_adv.asp
BioMedcentral 